\title{
Development and test-retest reliability of the Food Photograph Scale for Brazilian adults
}

\author{
Maria Fernanda Laus ${ }^{1}$, Natalia Louise Lima ${ }^{2}$, Telma Maria Braga Costa ${ }^{2}$, Marina Rodrigues \\ Barbosa $^{3}$, Paula Carolina Barboni Dantas Nascimento ${ }^{4}$, and Sebastião de Sousa Almeida ${ }^{1}$ \\ 1- Universidade de São Paulo, Ribeirão Preto, SP, Brazil \\ 2- Universidade de Ribeirão Preto, Ribeirão Preto, SP, Brazil \\ 3- Universidade Federal de São Carlos, São Carlos, SP, Brazil \\ 4- Defensoria Pública do Estado de São Paulo, Ribeirão Preto, SP, Brazil
}

\begin{abstract}
The study of food practices in Brazil faces important problems because of the nonexistence of properly tested methods and lack of a gold-standard instrument. Furthermore, only one instrument is capable of measuring food choice or knowledge in this specific population. In the present study we sought to develop a rapid assessment tool for food choice, consumption, and knowledge about healthy foods and test the reliability of the assessment tool in young adults as an initial step in the validation process. The scale was composed of 22 photographs of foods that were ready to consume, divided into "healthy" and "unhealthy" groups typically eaten as an afternoon snack in our region. To test the reliability of the instrument, 101 college students (51 males) were asked to select three items in response to three questions: "What would you like to eat as an afternoon snack?" "What do you consider healthy?" "What do you usually eat?" The procedure was repeated in the same subjects 1 month after the first application of the instrument. Results indicated a perfect reliability $(\kappa=1.0)$ among men when asked to select what they would like to eat, and perfect reliability was found among men and women when asked to select foods that they considered healthy. Excellent reliability $(\kappa>.75)$ was found among women and the total sample for foods they would like to eat and among men and women for what they usually eat. As an initial step in validating the instrument, the results suggested that it was properly developed and had reliability in the present context for studies that involve eating behavior. Keywords: reproducibility of results, food habits, food choice, knowledge, scale, photographs, food.
\end{abstract}

Received 8 January 2013; received in revised form 29 April 2013; accepted 3 May 2013. Available online 27 June 2013.

\section{Introduction}

Food practices are framed by a multilayer process that includes several biological, socio-cultural, and anthropological determinants, and they are shaped by

Maria Fernanda Laus and Sebastião de Sousa Almeida, Laboratório de Nutrição e Comportamento, Departamento de Psicologia, Faculdade de Filosofia, Ciências e Letras de Ribeirão Preto, Universidade de São Paulo, Ribeirão Preto, São Paulo, Brazil. Natalia Louise Lima and Telma Maria Braga Costa, Nutrição, Universidade de Ribeirão Preto, Ribeirão Preto, São Paulo, Brazil. Marina Rodrigues Barbosa, Laboratório de Fisiologia do Exercício, Departamento de Ciências Fisiológicas, Universidade Federal de São Carlos, São Carlos, São Paulo, Brazil. Paula Carolina Barboni Dantas Nascimento, Centro de Atendimento Multidisciplinar da Defensoria Pública do Estado de São Paulo, Ribeirão Preto, São Paulo, Brazil. Correspondence regarding this article should be directed to: Sebastião Sousa Almeida, Laboratório de Nutrição e Comportamento, Departamento de Psicologia, Faculdade de Filosofia, Ciências e Letras de Ribeirão Preto, Universidade de São Paulo, Av. Bandeirantes, 3900, Monte Alegre, Ribeirão Preto, SP, 14040-901, Brazil. Phone: +55 16 3602 3663. E-mail: sebasalm@usp.br individual situations (Gedrich, 2003; Jomori, Proença, \& Calvo, 2008). They also include both observed practices and subjective aspects such as norms, opinions, values, symbolic representations, and food choices in specific situations (Garcia, 1997; Poulan \& Proença, 2003). Food choices are influenced by the degree of freedom that each person has (Grunert, 1993); therefore, the choice that an individual makes at a certain moment or in a specific situation does not necessarily correspond to his/her habitual behavior.

A metaphoric framework-the food-choice kaleidoscope-was recently proposed by Jaeger, Bava, Worch, Dawson, \& Marshall (2011) as an approach to study food choices that conceptualize individual food choice events (i.e., occasions for eating) as being shaped by three main factors: product, person, and place. Therefore, as such a complex process, the study of food practices faces some critical problems. An important consideration is what investigators want to study so that they select the most appropriate instrument for each objective by considering the nature of the data (e.g., what individuals really do, what they say they do, 
and their opinions, attitudes, values, preferences, and knowledge; Poulan \& Proença, 2003).

Food liking is one aspect of food practices and eating behavior that has been recently investigated. One way to assess it is by using a technique that analyzes taste reactivity patterns and involves the careful assessment of hedonic and aversive behavioral reactions that are thought to be universal affective expressions and often correspond to human subjective ratings of palatability (Finlayson, King, \& Blundell, 2007). According to these authors, although easy to conduct, these types of tests are considerably different from free-living eating situations. Subjective liking may also be evaluated using analog scales (e.g., the Labeled Affective Magnitude [LAM] scale) in which participants are instructed to mark a line that corresponds to their level of liking after tasting a food (Havermans, Janssen, Giesen, Roefs, \& Jansen, 2009; Dressler \& Smith, 2013). Nevertheless, the limitations of this methodology include the number of foods presented and tasted, which may lead to sensory fatigue and influence the participant's appetite and rating of liking (Dressler \& Smith, 2013). Importantly, ratings of liking alone only provide evidence of food preference and cannot predict subsequent intake.

Several instruments and methodologies have been used to study food intake. The best-known of these include food records, 24-h dietary recall, and food frequency questionnaires, each with its own advantages and disadvantages. Food records consist of documenting all of the foods and drinks ingested and their respective quantities during a certain period of time, usually 3 to 7 days. This has been historically considered to be a very precise method that does not depend on memory but requires tremendous commitment and comprehension by the individual. Food records also take substantial time and can lead people to change their eating patterns (Johnson, 2002). Twenty-four-hour dietary recall is a snapshot of what an individual ate the day before. It is a relatively short interview that does not require as much literacy or motivation as the dietary record (Rockett, Berkey, \& Colditz, 2003). However, 24-h dietary recall does not provide an accurate picture of habitual food practices. It may assess an atypical day in an individual's life and depends on memory. Food frequency questionnaires comprise a list of food, and respondents report the frequency of ingesting each item (i.e., the number of times per day, week, or month; Cade, Thompson, Burley, \& Warm, 2002). It is a relatively quick and low-cost method, but it depends on memory. Additionally, some of the questionnaires are excessively long and may not contain some types of food (Salvo \& Gimeno, 2002; Ribeiro, Sávio, Rodrigues, Costa, \& Schmitz, 2006).

According to Harrison \& Jackson (2009), attitudes about food are commonly based on preoccupations about health, and food is commonly classified as "healthy" (paired with descriptors such as "good") and "unhealthy" (paired with descriptors such as "bad"). Thus, instruments that can identify a person's knowledge about what is healthy and unhealthy are useful. Food knowledge has been related to food practices (Watson, Kwon, Nichols, \& Rew, 2009). Some authors have suggested that a person's diet can be inappropriate without sufficient knowledge (Lin, Hang, Yang, \& Hung, 2011). Usually, this information is assessed by questionnaires such as the one developed by Parmenter \& Wardle (1999), which covers current dietary recommendations, sources of nutrients, everyday food choices, and diet-disease relationships. Another questionnaire developed by Anderson, Bell, Adamson, \& Moynihan (2002) assesses knowledge about applied nutrition. Nevertheless, these methods require high literacy and take much time to administer.

Another way to assess food practices, one that is rarely used but has numerous advantages, is the picturesort food instrument. One of the first such instruments was proposed by Kumanyika, Tell, Fried, Martel, \& Chinchilli (1996) and Kumanyika, Tell, Shemanski, Martel, \& Chinchilli (1997) to be used in adults. It comprises a set of foods and drinks represented as pictures on cards, and individuals are required to report the consumption frequency and portion size for each food. Jonsson, Gummeson, Conner, \& Svensson (1998) and Yaroch, Resnicow, Davis, Davis, Smith, \& Khan (2000) subsequently developed and tested similar instruments for children and adolescents, respectively. This method considers cognitive factors, reduces literacy demands, is more pleasant to the respondents, may be applicable to cross-cultural studies, and is quicker to administer than other methodologies (Kumanyika et al., 1996, 1997; Yaroch et al., 2000). Likewise, the photographs may be adapted to various questions (Jonsson et al., 1998).

In research on aspects of food practices, the selection and development of instruments are critical factors in the delineation process (Slater, Philippi, Marchioni, \& Fisberg, 2003). The selection of the proper tool for a particular study must consider the motivation, cognitive ability, and literacy level of the participants, size and location of the population to be studied, amount of funding for the study, and details about the nutrients and food (Rockett et al., 2003). Additionally, a successful instrument needs to be relatively short, easily administered, inexpensive, accurate, and usable in a broad range of subpopulations.

The initial steps in the development of an instrument require the definition of the nutrient/food group of interest, choice of appropriate foods that will appear on the instrument, number of food items, portion size, and target population. The method must then be tested and validated. The validity of an instrument must be tested to determine whether the technique measures what it is intended to measure and whether the findings of a study provide a reasonable representation of the true situation (Cade et al., 2002; Slater et al., 2003; Magarey et al., 2011). Among the types of validities that exist, three main categories are usually used: content, construct, and criterion. According to Parmenter \& Wardle (2000, p. 273), "Content validity...can be evidenced by a detailed 
description and justification of the content; by careful construction of items, response formats and layout; and by independent reviews from a panel of experts on both content and interpretability." Construct validity, also referred to as discriminatory validity, may be assessed by applying the instrument in two different groups and comparing the outcomes, which must present distinct results (Feren, Torheim, \& Lillegaard, 2011). Criterion validity indicates whether the construct is significantly and substantively correlated with measures of behavior (Sapp \& Jensen, 1997) in which the instrument being tested is often compared with another preexisting method. Several authors agree that the most acceptable approach to determine the criterion validity of tools that are designed to measure energy intake is the Doubly Labeled Water method (Schoeller, Ravussin, Schutz, Acheson, Baertschi, \& Jequier, 1986; Hill \& Davies, 2001; Johnson, 2002; Raymond, Peterson, Bartholome, Raatz, Jensen, \& Levine, 2012). However, because it is expensive, requires a high level of technical and analytical expertise, and is associated with the challenge of collecting daily urine samples from the subjects, this level of evaluation is rare (Collins et al., 2013).

Importantly, not all validation processes can be conducted for some outcomes, but repeatability can be assessed (Parmenter \& Wardle, 2000; Wilson, Magarey, $\&$ Mastersson, 2008). Scales that are designed to measure abstract attributes such as knowledge and attitudes may have content and construct validity explored but not criterion validity (for review, see Parmenter \& Wardle, 2000). The reproducibility or reliability of data consists of applying the instrument in the same group of people at least twice after a specific period of time, often 15 days to 1 month. Despite its importance, the assessment of test-retest reliability was not performed for the picture-sort food instruments mentioned above. The only exception is the instrument developed by Yaroch et al. (2000) that presented low reliability, ranging from 0.28 to 0.36 during a 2 -week period. Cade et al. (2002) reviewed studies of the development, validation, and utilization of food-frequency questionnaires and concluded that less than half of the instruments had their reproducibility tested; among those that were tested, correlation coefficients between 0.5 and 0.7 were the most common.

Valid information about food practices and food choices and knowledge about healthy diets are essential bases for nutritional recommendations, public health policies, and epidemiological research on the relationships between food practices and a person's general health (Hill \& Davies, 2001). However, exploration of these aspects requires the use of several distinct instruments that are often long and exhaustive and demand high literacy in the target population. Thus, the present study sought to develop a rapid assessment tool-the Food Photographs Scale - that qualifies individuals' food choices, consumption, and knowledge as "healthy" or "less healthy" and tested its reliability in young adults as an initial step in its adaptation process.

\section{Methods}

\section{Development of the Food Photographs Scale}

The first consideration when developing the scale was the meal that would be represented. After a long discussion among experts in the fields of nutrition and psychology, afternoon snacks were chosen because they are a quick meal that is generally composed of only a few items, which would allow the scale to have less food variability. We then selected the items that would comprise the instrument. This procedure was conducted by two nutritionists and one psychologist who considered foods that are typically consumed as part of this meal in this specific population. Such foods were identified by previous studies (Marcondelli, Costa, \& Schmitz, 2008; Monteiro, Andrade, Zanirati, \& Silva, 2009). The nutritional content of each item was also considered.

Table 1 presents the nutrient composition of the items selected according to the U.S. Department of Agriculture National Nutrient Database for Standard Reference (U.S. Department of Agriculture, Agricultural Research Service, 2001). The items "natural sandwich," "chicken drumstick," and "fried pastry" were absent in the American database; thus the nutritional content of these foods were described using the Brazilian Table of Food Composition sponsored by the Brazilian Ministry of Health (Center for Studies and Research on Foods, 2011). We considered the amount of energy, fat (i.e., saturated fat, unsaturated fat, and cholesterol), and fiber contained in the food. Twenty-two items were selected and divided into two groups: "healthy" and "less healthy" (11 items each). The "healthy" group consisted of pineapple, apple, natural fruit juice, papaya, orange, banana, ready-to-eat cereal, yogurt, milk, cereal bar, and natural sandwich (i.e., made of whole-wheat bread, lettuce, carrot, and ricotta). Notice that the majority of these items provide few calories and have a low quantity of fat and reasonable fiber content. The ready-to-eat cereal is more caloric but has no fat and has a high fiber content. The cereal bar is highly energetic but provides a good source of unsaturated fat and fiber. Additionally, we included dairy products in this group. Although they presented a high fat content and no fiber, they are considered functional foods that are replete with bioactive peptides, probiotic bacteria, antioxidants, highly absorbable calcium, conjugated linoleic acid, and other biologically active components (Campos, 2013).

The "less healthy" group consisted of soft drink, chocolate ice cream, stuffed cake, hot dog, cheeseburger, chicken drumstick, stuffed biscuits, fried pastry (i.e., made of wheat flour and filled with cheese, meat, or other fillings), chocolate bar, potato chips, and popcorn. All of these items are extremely caloric and have a high amount of fat, especially saturated fat and cholesterol.

After the definition of the items that would comprise the instrument, the foods were prepared and place on a white plate to be photographed. All of the items are 
Table 1. Nutritional content per $100 \mathrm{~g}$ of the items on the scale

\begin{tabular}{|c|c|c|c|c|c|c|c|c|}
\hline Item & $\begin{array}{c}\text { Energy } \\
\text { (kcal) }\end{array}$ & $\begin{array}{l}\text { Protein } \\
\text { (g) }\end{array}$ & $\begin{array}{l}\text { Total lipids } \\
\text { (fat) } \\
\text { (g) }\end{array}$ & $\begin{array}{l}\text { Saturated } \\
\text { fatty acids } \\
\text { (g) }\end{array}$ & $\begin{array}{l}\text { Unsaturated } \\
\text { fatty acids } \\
\text { (g) }\end{array}$ & $\begin{array}{l}\text { Cholesterol } \\
\text { (mg) }\end{array}$ & $\begin{array}{c}\text { Carbohydrates } \\
\text { (g) }\end{array}$ & $\begin{array}{c}\text { Total } \\
\text { fiber } \\
\text { (g) }\end{array}$ \\
\hline \multicolumn{9}{|l|}{ Healthy } \\
\hline Pineapple & 48 & .54 & .12 & .01 & .06 & - & 12.63 & 1.40 \\
\hline Apple & 52 & .26 & .17 & .03 & .06 & - & 13.81 & 2.40 \\
\hline Natural fruit juice & 45 & .70 & .20 & .02 & .07 & - & 10.40 & .20 \\
\hline Papaya & 43 & .47 & .26 & .08 & .12 & - & 10.82 & 1.70 \\
\hline Orange & 63 & 1.30 & .30 & .03 & .11 & - & 15.5 & 4.50 \\
\hline Banana & 89 & 1.09 & .33 & .11 & .10 & - & 22.84 & 2.60 \\
\hline Ready-to-eat cereal & 357 & 7.50 & .40 & .12 & .26 & - & 84.10 & 3.30 \\
\hline Yogurt & 61 & 3.47 & 3.25 & 2.09 & .98 & 13.00 & 4.66 & - \\
\hline Milk & 64 & 3.28 & 3.66 & 2.28 & 1.19 & 14.00 & 4.65 & - \\
\hline Cereal bar & 409 & 9.09 & 9.09 & - & 8.62 & - & 72.73 & 1.80 \\
\hline Natural sandwich* & 159 & 8.79 & 4.68 & 2.05 & 1.77 & 24.5 & 19.29 & 3.83 \\
\hline \multicolumn{9}{|l|}{ Less Healthy } \\
\hline Soft drink & 42 & - & - & - & - & - & 10.6 & - \\
\hline Chocolate ice cream & 216 & 3.80 & 11.00 & 6.80 & 3.62 & 34.00 & 28.20 & 1.20 \\
\hline Stuffed cake & 371 & 5.66 & 14.33 & 9.16 & 5.16 & - & 55.00 & 1.33 \\
\hline Hot dog & 247 & 10.60 & 14.84 & 5.21 & 8.73 & 45.00 & 18.4 & - \\
\hline Cheeseburger & 313 & 14.48 & 14.85 & 6.34 & 7.17 & 49.00 & 31.13 & - \\
\hline Chicken drumstick* & 274 & 13.41 & 16.88 & 2.60 & 8.10 & 15.00 & 16.54 & .88 \\
\hline Stuffed biscuits & 466 & 5.33 & 19.08 & 3.68 & 12.89 & .00 & 71.64 & 2.90 \\
\hline Fried pastry* & 388 & 10.10 & 20.10 & 4.80 & 13.5 & 25.00 & 43.80 & 1.00 \\
\hline Chocolate bar & 505 & 3.90 & 34.20 & 20.08 & 12.21 & 4.65 & 59.59 & 5.5 \\
\hline Potato chips & 543 & 5.60 & 36.60 & 12.90 & 15.90 & - & 51.20 & 2.50 \\
\hline Popcorn & 583 & 7.29 & 43.55 & 6.82 & 33.00 & - & 45.06 & 8.10 \\
\hline
\end{tabular}

*According to the Brazilian Table of Food Composition.

presented in their final form (i.e., ready to eat). No packaging was shown, and all photographs correspond to one portion of the food, defined according to the parameters proposed by Monteiro \& Chiarello (2007). Foods were photographed and passed through imageprocessing software to improve picture quality. Each item was transformed into a $5.12 \times 5.12$ inch color photograph and covered by rigid transparent plastic with a blue background (Figure 1).

The instrument should be presented in a random order, and the participants must select three items from the set of photos that they would like to eat as an afternoon snack and three items that they considered healthy. The participants should also select the foods that comprise the meal that they usually eat. The main aim of the scale is to classify answers as "healthy" and "less healthy" to provide qualitative data. Therefore, the choices should be classified according to the majority of the answers (i.e., "healthy" is denoted when two or three items are from this group, and "less healthy" is denoted when two or three foods are from this group). Importantly, the participants are not aware that this response classification will be done. With regard to the third question (i.e., what the participants usually eat), in cases in which no items match their usual snack, the subjects should be oriented toward selecting a similar item.

\section{Test-retest reliability analysis}

A convenience sample of 101 college students (51 males and 50 females) from different courses at a private university in a city in the state of São Paulo, Brazil participated in the study. The sample size was based on the review by Cade et al. (2002) and previous studies that used the same methodology. The participants' ages ranged from 19 to 32 years. The inclusion criteria included age $>18$ years and being enrolled in one of the courses offered by the university. No participant attrition occurred between the two time-points of the study. Participation was completely voluntary and no rewards were given. Anthropometric characteristics of the sample are presented in Table 2.

The study was approved by the Academic and Ethics Committee of the University of Ribeirão Preto (UNAERP) and informed consent was obtained from all 


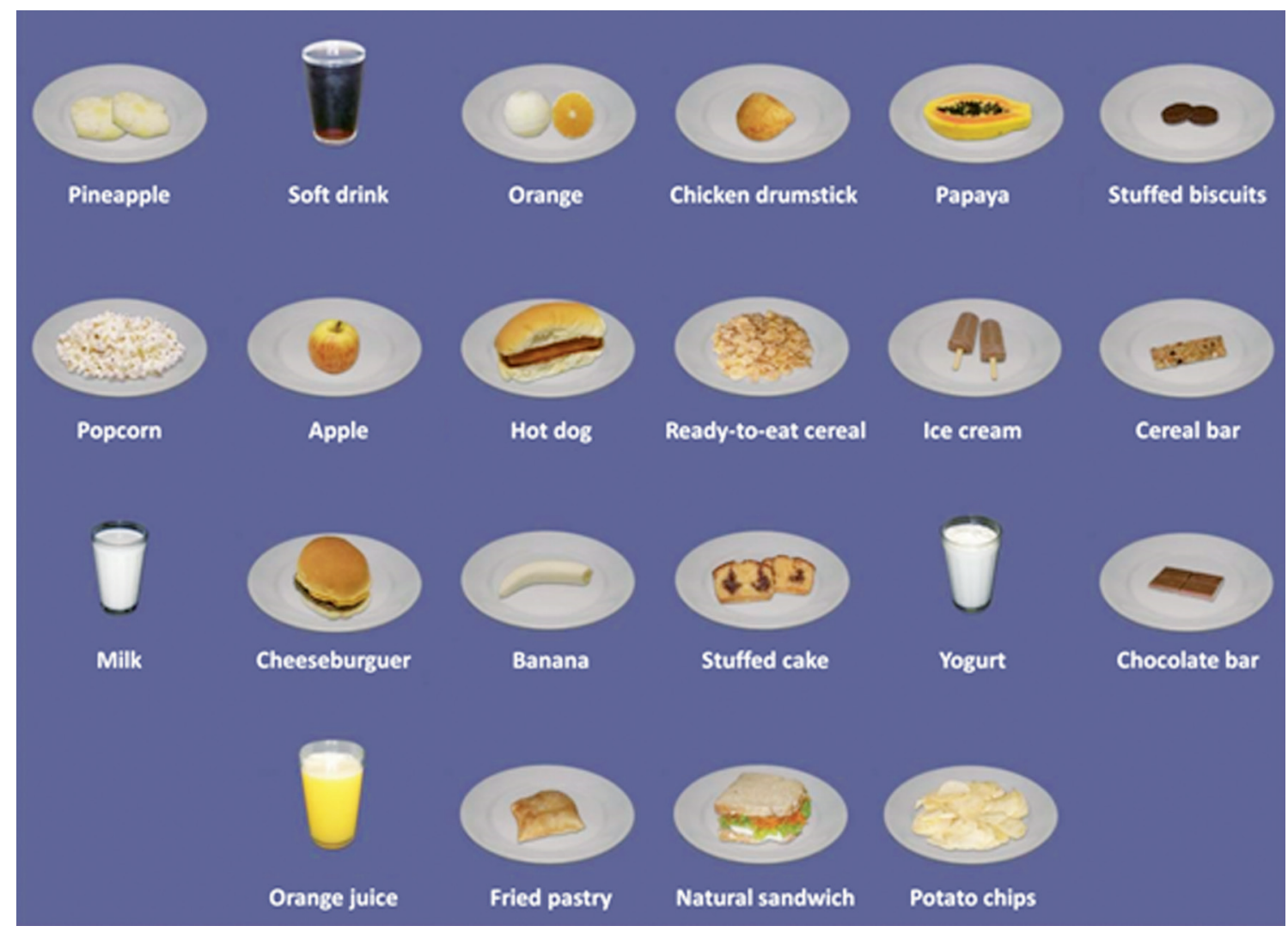

Figure 1. Food Photographs Scale.

Table 2. Descriptive anthropometric characteristics of the sample by gender $(n=101)$

\begin{tabular}{|c|c|c|c|}
\hline Sample & Men & Women & Total \\
\hline$n$ & 51 & 50 & 101 \\
\hline \multicolumn{4}{|c|}{ Age (years) } \\
\hline Mean & 22.41 & 22.82 & 22.61 \\
\hline SEM & .30 & .35 & .23 \\
\hline $95 \% \mathrm{CI}$ & $21.80-23.02$ & $22.11-23.52$ & $22.15-23.07$ \\
\hline Range & $19.0-30.0$ & $20.0-32.0$ & $19.0-32.0$ \\
\hline \multicolumn{4}{|c|}{ Weight (kg) } \\
\hline Mean & 77.96 & 63.42 & 70.76 \\
\hline SEM & 1.25 & 1.35 & 1.17 \\
\hline $95 \% \mathrm{CI}$ & $75.45-80.46$ & $60.70-66.13$ & $68.44-73.08$ \\
\hline Range & $62.5-94.0$ & $48.0-88.6$ & $48.0-94.0$ \\
\hline \multicolumn{4}{|l|}{ Height (m) } \\
\hline Mean & 1.77 & 1.66 & 1.72 \\
\hline SEM & .01 & .01 & .01 \\
\hline $95 \% \mathrm{CI}$ & $1.75-1.79$ & $1.63-1.67$ & $1.69-1.73$ \\
\hline Range & $1.60-1.92$ & $1.54-1.77$ & $1.54-1.92$ \\
\hline \multicolumn{4}{|c|}{ Body mass index $\left(\mathrm{kg} / \mathrm{m}^{2}\right)$} \\
\hline Mean & 24.85 & 23.17 & 24.02 \\
\hline SEM & .39 & .49 & .32 \\
\hline $95 \% \mathrm{CI}$ & $24.06-25.62$ & $22.18-24.14$ & $23.37-24.65$ \\
\hline Range & $19.01-30.69$ & $17.57-31.70$ & $17.57-31.70$ \\
\hline
\end{tabular}

CI, confidence interval. participants. Data were collected in a private room on the campus at two different times by a single researcher. During the first time-point of the study (i.e., test), the students were asked to participate by the researcher. After agreeing to participate, the test was conducted in the room. The participants were introduced to the Food Photographs Scale. After answering all of the questions, the participants' weights and heights were measured.

The second time-point of the study (i.e., re-test) occurred exactly 1 month later. The participants were contacted by the researchers and requested to attend at a specific time and location. The participants were asked to again answer the same three questions.

\section{Statistical analysis}

Statistical analyses were performed using SPSS 17.0 software. The Kolmogorov-Smirnov test indicated a normal distribution of the data. Anthropometric characteristics were described as means, standard errors of the mean (SEMs), 95\% confidence intervals, and ranges. The foods selected in response to each of the questions were evaluated as absolute frequencies and classified as "healthy" or "less healthy." According to the recommendations of Masson et al. (2003), test-retest reliability was evaluated using the kappa statistic. These authors stated that if categorical data are used, then the percentages should be classified into the same/opposite category, and the weighted kappa may provide a more appropriate performance indicator. Coefficients were classified according to the recommendations of Rosner 
(2010): $\kappa=1.0$ indicates perfect reproducibility, $\kappa>$ 0.75 indicates excellent reproducibility, $0.4 \leq \kappa \leq 0.75$ indicates good reproducibility, and $0 \leq \kappa \leq 0.4$ indicates marginal reproducibility.

\section{Results}

The reliability results of the scale for each question are presented in Table 3. High consistency was found for all of the questions $(\kappa>.70)$, indicating good agreement between food choices in the test-retest evaluation. Perfect reliability $(\kappa=1.0)$ was found among men when asked to select what they would like to eat. Perfect reliability was also found among men and women when asked to select foods they considered "healthy." Excellent reliability $(\kappa>.75)$ was found among women and the total sample for foods they would like to eat and among men and women for what they usually eat.

Tables 4, 5, and 6 present the number of times each item was chosen by men and women in response to each question in both applications of the instrument. Although some foods were chosen more or fewer times between the two applications of the instrument, the items were generally the same.

Table 3. Absolute frequency on test-retest of food choices and kappa coefficients for the Food Photographs Scale

\begin{tabular}{lccc}
\hline Sample & Men & Women & Total \\
\hline $\boldsymbol{n}$ & $\mathbf{5 1}$ & $\mathbf{5 0}$ & $\mathbf{1 0 1}$ \\
Would like to eat (test) & & & \\
$\quad$ Healthy & 12 & 10 & 22 \\
$\quad$ Less healthy & 39 & 40 & 79 \\
Would like to eat (re-test) & & & \\
$\quad$ Healthy & 12 & 9 & 21 \\
$\quad$ Less healthy & 39 & 41 & 80 \\
Kappa coefficient $(\kappa)$ & $1.0^{*}$ & $.935^{*}$ & $.942^{*}$ \\
\hline
\end{tabular}

Considered healthy (test)

\begin{tabular}{|c|c|c|c|}
\hline Healthy & 51 & 50 & 101 \\
\hline Less healthy & - & - & - \\
\hline \multicolumn{4}{|c|}{ Considered healthy (re-test) } \\
\hline Healthy & 51 & 50 & 101 \\
\hline Less healthy & - & - & - \\
\hline Kappa coeficient ( $(\kappa)$ & $1.0^{*}$ & $1.0^{*}$ & $1.0^{*}$ \\
\hline \multicolumn{4}{|l|}{ Usually eat (test) } \\
\hline Healthy & 29 & 36 & 65 \\
\hline Less healthy & 22 & 14 & 36 \\
\hline \multicolumn{4}{|l|}{ Usually eat (re-test) } \\
\hline Healthy & 34 & 38 & 72 \\
\hline Less healthy & 17 & 12 & 29 \\
\hline Kappa coefficient $(\kappa)$ & $.794 *$ & $.896^{*}$ & $.708^{*}$ \\
\hline
\end{tabular}

\section{Discussion}

In the present study we sought to develop a single, rapid assessment tool that qualifies individual food choices, consumption, and knowledge as "healthy" or "less healthy" and test its reliability in young adults. The perfect/excellent test-retest reliability results indicated that the measures remained unchanged 1 month after the first application of the instrument. Therefore, the instrument presented reliable and trustworthy data in the evaluation of food choices and consumption. The scale was also able to assess a person's knowledge about healthy foods.

The relevance of studying food habits is largely known. Using the instrument proposed herein, qualifying individuals' diets is possible, and populations can be identified that are at risk for developing health problems. The evaluation of possible associations between food consumption and health conditions is also possible. Little attention has been given to a person's food choices in specific situations. Such questions are important when considering that people choose food in a context-dependent manner (Falk, Sobal, Bisogni, Connors, \& Devine, 2001). Therefore, a measure that allows the qualification of choices under experimental or "real" conditions may be useful for identifying food choices in various situations. For example, within the food-choice kaleidoscope, photographs can be used to evaluate foods and beverages that are consumed (i.e., product), the contextual/environmental influences on choices (i.e., place), and how individuals differ with regard to their consumption (i.e., person; Jaeger et al., 2011). A practical application of the instrument within this perspective is the study by Laus (2013) who evaluated the effect of thin media images on undergraduates' food choices. The author asked men and women to select three items from the set of 22 foods that they would like to eat as an afternoon snack. The participants were then presented with images of individuals who represented the ideal body propagated by the media. The participants were then asked again to select the food that they would like to eat. The results from this study demonstrated that the scale was able to assess students' choices and capture differences between the two times of evaluation.

Evaluating individual's knowledge about healthy and unhealthy foods is also important in which the classification of foods is a critical component of the process of making food choices. Consciousness about what is good or not good for health has been identified as frequently occurring when selecting everyday food (Falk et al., 2001). Harrison \& Jackson (2009) discussed what makes a food "healthy." In their study, young participants maintained that healthy foods are natural and nutritious (i.e., the foods have nothing "bad" added and nothing removed). Unlike healthy foods, unhealthy foods were thought to be artificial and unnatural (i.e., foods that are processed or contain artificial ingredients or excessive sugar or fat). All of the participants in our study demonstrated that they knew what is or is 
Table 4. Number of times each item was selected at the two time-points of the study by men and women when asked to select the three items they would like to eat

\begin{tabular}{|c|c|c|c|c|c|c|c|}
\hline \multicolumn{4}{|c|}{ Men } & \multicolumn{4}{|c|}{ Women } \\
\hline \multicolumn{2}{|l|}{ Test } & \multicolumn{2}{|l|}{ Re-test } & \multicolumn{2}{|l|}{ Test } & \multicolumn{2}{|l|}{ Re-test } \\
\hline Item & $\begin{array}{c}\text { No. } \\
\text { choices }\end{array}$ & Item & $\begin{array}{c}\text { No. } \\
\text { choices }\end{array}$ & Item & $\begin{array}{c}\text { No. } \\
\text { choices }\end{array}$ & Item & $\begin{array}{l}\text { No. } \\
\text { choices }\end{array}$ \\
\hline Soft drink & 19 & Soft drink & 18 & Natural fruit juice & 16 & Natural fruit juice & 18 \\
\hline Cereal bar & 14 & Natural fruit juice & 15 & Soft drink & 14 & Soft drink & 16 \\
\hline Natural fruit juice & 14 & Natural sandwich & 14 & Stuffed cake & 13 & Yogurt & 13 \\
\hline Potato chips & 14 & Cheeseburger & 13 & Yogurt & 12 & Popcorn & 12 \\
\hline Cheeseburger & 13 & Stuffed biscuits & 12 & Natural sandwich & 10 & Natural sandwich & 11 \\
\hline Natural sandwich & 12 & Cereal bar & 9 & Popcorn & 9 & Stuffed cake & 11 \\
\hline Stuffed cake & 10 & Chocolate bar & 9 & Cereal bar & 8 & Chocolate ice cream & 10 \\
\hline Stuffed biscuits & 9 & Chocolate ice cream & 8 & Hot dog & 8 & Hot dog & 9 \\
\hline Yogurt & 7 & Potato chips & 8 & Chocolate ice cream & 8 & Chocolate bar & 9 \\
\hline Chocolate bar & 6 & Hot dog & 7 & Chocolate bar & 8 & Stuffed biscuits & 8 \\
\hline Popcorn & 5 & Apple & 6 & Fried pastry & 8 & Cereal bar & 7 \\
\hline Milk & 4 & Ready-to-eat cereal & 6 & Cheeseburger & 6 & Cheeseburger & 7 \\
\hline Apple & 4 & Stuffed cake & 6 & Pineapple & 5 & Pineapple & 5 \\
\hline Ready-to-eat cereal & 4 & Banana & 5 & Chicken drumstick & 5 & Banana & 3 \\
\hline Hot dog & 4 & Chicken drumstick & 4 & Potato chips & 5 & Potato chips & 3 \\
\hline Chocolate ice cream & 4 & Popcorn & 4 & Banana & 4 & Milk & 2 \\
\hline Chicken drumstick & 4 & Yogurt & 3 & Stuffed biscuits & 4 & Apple & 2 \\
\hline Papaya & 2 & Fried pastry & 3 & Milk & 2 & Fried pastry & 2 \\
\hline Banana & 2 & Milk & 2 & Apple & 2 & Orange & 1 \\
\hline Orange & 1 & Pineapple & 1 & Orange & 2 & Chicken drumstick & 1 \\
\hline Fried pastry & 1 & Orange & 一 & Papaya & 1 & Papaya & - \\
\hline Pineapple & - & Papaya & - & Ready-to-eat cereal & - & Ready-to-eat cereal & - \\
\hline
\end{tabular}

Table 5. Number of times each item was selected at the two time-points of the study by men and women when asked to select the items they usually eat

\begin{tabular}{|c|c|c|c|c|c|c|c|}
\hline \multicolumn{4}{|c|}{ Men } & \multicolumn{4}{|c|}{ Women } \\
\hline \multicolumn{2}{|l|}{ Test } & \multicolumn{2}{|l|}{ Re-test } & \multicolumn{2}{|l|}{ Test } & \multicolumn{2}{|l|}{ Re-test } \\
\hline Item & $\begin{array}{c}\text { No. } \\
\text { choices }\end{array}$ & Item & $\begin{array}{c}\text { No. } \\
\text { choices }\end{array}$ & Item & $\begin{array}{c}\text { No. } \\
\text { choices }\end{array}$ & Item & $\begin{array}{c}\text { No. } \\
\text { choices }\end{array}$ \\
\hline Cereal bar & 28 & Natural sandwich & 27 & Natural sandwich & 26 & Cereal bar & 25 \\
\hline Natural sandwich & 23 & Cereal bar & 22 & Natural fruit juice & 25 & Natural fruit juice & 23 \\
\hline Natural fruit juice & 21 & Natural fruit juice & 20 & Cereal bar & 23 & Natural sandwich & 20 \\
\hline Banana & 19 & Stuffed biscuits & 17 & Banana & 12 & Banana & 18 \\
\hline Milk & 16 & Soft drink & 14 & Milk & 8 & Stuffed biscuits & 14 \\
\hline Stuffed biscuits & 12 & Banana & 13 & Stuffed biscuits & 8 & Apple & 8 \\
\hline Soft drink & 10 & Milk & 12 & Yogurt & 7 & Stuffed cake & 8 \\
\hline Apple & 5 & Potato chips & 4 & Stuffed cake & 7 & Milk & 6 \\
\hline Fried pastry & 4 & Apple & 3 & Apple & 6 & Soft drink & 6 \\
\hline Chicken drumstick & 2 & Stuffed cake & 3 & Soft drink & 5 & Potato chips & 5 \\
\hline Yogurt & 1 & Fried pastry & 2 & Potato chips & 3 & Yogurt & 4 \\
\hline Stuffed cake & 1 & Chicken drumstick & 1 & Fried pastry & 2 & Chocolate bar & 1 \\
\hline Pineapple & - & Cheeseburger & 1 & Pineapple & 1 & Pineapple & - \\
\hline Orange & - & Chocolate bar & 1 & Orange & - & Orange & - \\
\hline Papaya & - & Pineapple & - & Papaya & - & Papaya & - \\
\hline Ready-to-eat cereal & - & Orange & - & Ready-to-eat cereal & - & Ready-to-eat cereal & - \\
\hline Hot dog & - & Papaya & - & Hot dog & - & Hot dog & - \\
\hline Chocolate ice cream & - & Ready-to-eat cereal & - & Chocolate ice cream & - & Chocolate ice cream & - \\
\hline Cheeseburger & - & Yogurt & - & Chicken drumstick & - & Chicken drumstick & - \\
\hline Chocolate bar & - & Hot dog & - & Cheeseburger & - & Cheeseburger & - \\
\hline Popcorn & - & Chocolate ice cream & - & Chocolate bar & - & Fried pastry & - \\
\hline Potato chips & - & Popcorn & - & Popcorn & - & Popcorn & - \\
\hline
\end{tabular}


Table 6. Number of times each item was selected at the two time-points of the study by men and women when asked to select the three items considered healthy

\begin{tabular}{|c|c|c|c|c|c|c|c|}
\hline \multicolumn{4}{|c|}{ Men } & \multicolumn{4}{|c|}{ Women } \\
\hline \multicolumn{2}{|l|}{ Test } & \multicolumn{2}{|c|}{ Re-test } & \multicolumn{2}{|l|}{ Test } & \multicolumn{2}{|l|}{ Re-test } \\
\hline Item & $\begin{array}{l}\text { No. } \\
\text { choices }\end{array}$ & Item & $\begin{array}{l}\text { No. } \\
\text { choices }\end{array}$ & Item & $\begin{array}{l}\text { No. } \\
\text { choices }\end{array}$ & Item & $\begin{array}{l}\text { No. } \\
\text { choices }\end{array}$ \\
\hline Natural sandwich & 25 & Papaya & 23 & Yogurt & 20 & Apple & 20 \\
\hline Ready-to-eat cereal & 24 & Natural sandwich & 22 & Pineapple & 18 & Natural fruit juice & 17 \\
\hline Natural fruit juice & 19 & Milk & 19 & Cereal bar & 18 & Pineapple & 16 \\
\hline Papaya & 18 & Ready-to-eat cereal & 18 & Natural sandwich & 17 & Milk & 16 \\
\hline Orange & 14 & Banana & 16 & Apple & 16 & Banana & 15 \\
\hline Yogurt & 13 & Natural fruit juice & 14 & Milk & 14 & Natural sandwich & 14 \\
\hline Banana & 12 & Pineapple & 12 & Papaya & 12 & Papaya & 14 \\
\hline Milk & 11 & Orange & 12 & Natural fruit juice & 11 & Cereal bar & 12 \\
\hline Pineapple & 8 & Cereal bar & 7 & Banana & 10 & Orange & 12 \\
\hline Cereal bar & 5 & Apple & 7 & Orange & 9 & Yogurt & 11 \\
\hline Apple & 4 & Yogurt & 3 & Ready-to-eat cereal & 5 & Ready-to-eat cereal & 3 \\
\hline Hot dog & - & Hot dog & - & Hot dog & - & Hot dog & - \\
\hline $\begin{array}{c}\text { Chocolate ice } \\
\text { cream }\end{array}$ & - & $\begin{array}{c}\text { Chocolate ice } \\
\text { cream }\end{array}$ & - & $\begin{array}{c}\text { Chocolate ice } \\
\text { cream }\end{array}$ & - & $\begin{array}{c}\text { Chocolate ice } \\
\text { cream }\end{array}$ & - \\
\hline Stuffed cake & - & Stuffed cake & - & Stuffed cake & - & Stuffed cake & - \\
\hline Chicken drumstick & - & Chicken drumstick & - & Chicken drumstick & - & Chicken drumstick & - \\
\hline Cheeseburger & - & Cheeseburger & - & Cheeseburger & - & Cheeseburger & - \\
\hline Stuffed biscuits & - & Stuffed biscuits & - & Stuffed biscuits & - & Stuffed biscuits & - \\
\hline Chocolate bar & - & Chocolate bar & - & Chocolate bar & - & Chocolate bar & - \\
\hline Fried pastry & - & Fried pastry & - & Fried pastry & - & Fried pastry & - \\
\hline Soft drink & - & Soft drink & - & Soft drink & - & Soft drink & - \\
\hline Popcorn & - & Popcorn & - & Popcorn & - & Popcorn & - \\
\hline Potato chips & - & Potato chips & - & Potato chips & - & Potato chips & - \\
\hline
\end{tabular}

not healthy. However, when asked about the food they would like to eat, the majority of the participants $(n=$ 79) selected less healthy items. Moreover, more than a third of the participants reported that they usually eat this kind of food.

Such information is extremely useful in the area of public health because knowledge is not necessarily related to healthy eating habits, leading to the necessity of reevaluating campaigns to improve people's diets through nutritional education alone. Actual programs may be too focused on prevention via information. As suggested by Harrison \& Jackson (2009), focus should be placed on motivation, meaning, values, and attitudes toward dietary habits as a means of understanding these behaviors.

The proposed method has several limitations. It depends on the individual's memory when used to qualify usual consumption. It also does not quantify people's intake and has a limited number of food items. Incomplete data related to the validity of the scale is also a limitation. Although testing criterion validity is not possible in measures that assess nutritional knowledge and food choices, content and construct validity can be investigated. Thus, studies of this nature should be conducted with the present scale. Finally, test-retest reliability assessed in the present study cannot detect the existence of systematic error. One problem with using the identical test for test-retest reliability is that individuals may learn from the first administration and carry such learning over to the next session (Talmage \& Rasher, 1981).

\section{Conclusion}

Despite its limitations, the Food Photographs Scale can provide information about whether subjects usually consume "healthy" foods and classify this trait with regard to foods that individuals choose in specific situations. The scale also provides information about a person's knowledge about healthy foods. Importantly, the Food Photographs Scale is not an instrument that is intended to explain the responses to these questions but rather describe them. As cited elsewhere, methodologies that utilize food photographs have numerous advantages. They require a lower literacy level and engage the participant. They can be used for different subpopulations and different ages, and the time necessary for administration is less than or equal to the time required for other instruments. Moreover, the scale proposed herein may be adapted to several situations, conditions, and populations. Researchers interested in using this methodology may increase the number of items including country/location-specific foods or adapt it for use with different ranges of ages.

Thus, the initial phase of the adaptation of the Food Photographs Scale for young adults suggested that the instrument was developed appropriately and 
had reliability in the present context for investigations that involve food choice and consumption and people's knowledge about healthy foods.

\section{Acknowledgements}

The authors are grateful to the National Council for Scientific and Technological Development (CNPq; Process no. 141455/2009-8) and University of Ribeirao Preto for financial support.

\section{References}

Anderson, A. S., Bell, A., Adamson, A., \& Moynihan, P. (2002). A questionnaire assessment of nutrition knowledge: Validity and reliability issues. Public Health Nutrition, 5(3), 497-503.

Cade, J., Thompson, R., Burley, V., \& Warm, D. (2002). Development, validation and utilisation of food-frequency questionnaires: A review. Public Health Nutrition, 5(4), 567-587.

Campos, L. (2013). Campaña Panamericana de consume de lácteosBenefícios dos produtos lácteos no tratamento e prevenção da hipertensão e diabetes [Benefits of dairy products for the treatment and prevention of hypertension and diabetes]. [http://www. produccion-animal.com.ar/produccion_bovina_de_leche/leche subproductos/07-Licinia de Campos.pdf; accessed May 23, 2013]

Center for Studies and Research on Foods (2011). Tabela Brasileira de composição de alimentos [Brazilian table of food composition]. Campinas: NEPA-UNICAMP. [www.unicamp.br/nepa/taco; accessed May 23, 2013]

Collins, C. E., Burrows, T. L., Truby, H., Morgan, P. J., Wright, I. M. R., Davies, P. S. W., \& Callister, R. (2013). Comparison of energy intake in toddlers assessed by food frequency questionnaire and total energy expenditure measured by the doubly labeled water method. Journal of the Academy of Nutrition and Dietetics, 113(3), 459-463.

Dressler, H., \& Smith, C. (2013). Food choice, eating behavior, and food liking differs between lean/normal and overweight/obese, low-income women. Appetite, 65(1), 145-152.

Falk, L. W., Sobal, J., Bisogni, C. A., Connors, M., \& Devine, C. M. (2001). Managing healthy eating: Definitions, classifications, and strategies. Health Education \& Behavior, 28(4), 425-439.

Feren, A., Torheim, L. E., \& Lillegaard, I. T. L. (2011). Development of a nutrition knowledge questionnaire for obese adults. Food \& Nutrition Research, 55, doi: 10.3402/fnr.v55i0.7271.

Finlayson, G., King, N., \& Blundell, J. E. (2007). Liking vs. wanting food: importance for human appetite control and weight regulation. Neuroscience and Biobehavioral Reviews, 31(7), 987-1002.

Garcia, R. W. D. (1997). Representações sociais da alimentação e saúde e suas repercussões no comportamento alimentar [Social representations of health and nutrition and its effects on eating behavior]. PHYSIS: Revista de Saúde Coletiva, 7(2), 51-68.

Gedrich, K. (2003). Determinants of nutritional behaviour: A multitude of levers for successful intervention? Appetite, 41(3), 231-238.

Grunert, K. G. (1993). Towards a concept of food-related life style. Appetite, 21(2), 151-155.

Harrison, M., \& Jackson, L. A. (2009). Meanings that youth associate with healthy and unhealthy food. Canadian Journal of Dietetic Practice and Research, 70(1), 6-12.

Havermans, R. C., Janssen, T., Giesen, J. C. A. H., Roefs, A., \& Jansen, A. (2009). Food liking, food wanting, and sensory-specific satiety. Appetite, 52(1), 222-225.

Hill, R. J., \& Davies, P. S. W. (2001). The validity of self-reported energy intake as determined using the doubly labelled water technique. British Journal of Nutrition, 85(4), 415-430.

Jaeger, S. R., Bava, C. M., Worch, T., Dawson, J., \& Marshall, D. W. (2011). The food choice kaleidoscope: a framework for structured description of product, place and person as sources of variation in food choices. Appetite, 56(2), 412-423.

Johnson, R. K. (2002). Dietary intake: How do we measure what people are really eating? Obesity Research, 10(Suppl. 1), 63S-68S.

Jomori, M. M., Proença, R. P. C., \& Calvo, M. C. M. (2008). Determinantes da escolha alimentar [Food choice factors]. Revista de Nutrição, 21(1), 63-73.

Jonsson, I., Gummeson, L., Conner, M., \& Svensson, E. (1998). Assessing food choice in school children: Reliability and construct validity of a method stacking food photographs. Appetite, 30(1), 25-37.
Kumanyika, S., Tell, G. S., Fried, L., Martel, J. K., \& Chinchilli, V. M. (1996). Picture-sort method for administering a food frequency questionnaire to older adults. Journal of the American Dietetic Association, 96(2), 137-144.

Kumanyika, S., Tell, G. S., Shemanski, L., Martel, J., \& Chinchilli, V. M. (1997). Dietary assessment using a picture-sort approach. American Journal of Clinical Nutrition, 65(Suppl.), 1123S-1129S.

Laus M. F. (2013). Influência do padrão de beleza veiculado pela mídia na satisfação corporal e escolha alimentar de adultos [Influence of the standard of beauty transmitted by the media on body satisfaction and food choice in adults]. Unpublished doctoral thesis. São Paulo: University of São Paulo.

Lin, W., Hang, C. M., Yang, H. C., \& Hung, M. H. (2011). 2005-2008 Nutrition and Health Survey in Taiwan: the nutrition knowledge, attitude and behavior of 19-64 year old adults. Asia Pacific Journal of Clinical Nutrition, 20(2), 309-318.

Magarey, A., Watson, J., Golley, R. K., Burrows, T., Sutherland, R., McNaughton, S. A., Denney-Wilson, E., Campbell, K., \& Collins, C. (2011). Assessing dietary intake in children and adolescents: considerations and recommendations for obesity research. International Journal of Pediatric Obesity, 6(1), 2-11.

Marcondelli, P., Costa, T. H. M., \& Schmitz, B. A. S. (2008). Nível de atividade física e hábitos alimentares de universitários do $3^{\circ}$ ao $5^{\circ}$ semestres da área da saúde [Physical activity level and food intake habits of university students from 3 to 5 semester in the health area]. Revista de Nutrição, 21(1), 39-47.

Masson, L. F., McNeil, G., Tomany, J. O., Simpson, J. A., Peace, H. S., Wei, L., Grubb, D. A., \& Bolton-Smith, C. (2003). Statistical approaches for assessing the relative validity of a food-frequency questionnaire: use of correlation coefficients and the kappa statistics. Public Health Nutrition, 6(3), 313-321.

Monteiro, J. P., \& Chiarello, P. G. (2007). Consumo alimentar: visualizando porções [Food consumption: Visualizing portions]. Rio de Janeiro: Guanabara Koogan.

Monteiro, M. R. P., Andrade, M. L. O., Zanirati, V. F., \& Silva, R. R. (2009). Hábito e consumo alimentar de estudantes do sexo feminino dos cursos de nutrição e de enfermagem de uma universidade pública brasileira [Eating habits and intake of female students of nutrition and nursing in a Brazilian public university]. Revista APS, 12(3), 271-277.

Parmenter, K., \& Wardle, J. (2000). Evaluation and design of nutrition knowledge measures. Journal of Nutrition Education, 32(5), 269277.

Poulain, J., \& Proença, R. P. C. (2003). Reflexões metodológicas para o estudo das práticas alimentares [Methodological approaches on the studies of food practices]. Revista de Nutrição, 16(4), 365-386.

Raymond, N. C., Peterson, R. E., Bartholome, L. T., Raatz, S. K., Jensen, M. D., \& Levine, J. A. (2012). Comparisons of energy intake and energy expenditure in overweight and obese women with and without binge eating disorder. Obesity, 20(4), 765-772.

Ribeiro, A. C., Sávio, K. E. O., Rodrigues, M. L. C. F., Costa, T. H. M., \& Schmitz, B. A. S. (2006). Validação de um questionário de frequência de consumo alimentar para população adulta [Validation of a food frequency questionnaire for the adult population]. Revista de Nutrição, 19(5), 553-562.

Rockett, H. R. H., Berkey, C. S., \& Colditz, G. A. (2003). Evaluation of dietary assessment instruments in adolescents. Current Opinion in Clinical Nutrition and Metabolic Care, 6(5), 557-562.

Rosner, B. A. (2010). Fundamentals of biostatistics. Belmont: Pacific Grove.

Salvo, V. L. M. A., \& Gimeno, S. G. A. (2002). Reprodutibilidade e validade do questionário de frequência de consumo de alimentos [Reproducibility and validity of a food frequency questionnaire]. Revista de Saúde Pública, 36(4), 505-512.

Sapp, S. G., \& Jensen, H. H. (1997). Reliability and validity of nutrition knowledge and diet-health awareness tests developed from the 1989-1991 Diet and Health Knowledge Surveys. Journal of Nutrition Education, 29(2), 63-72.

Schoeller, D. A., Ravussin, E., Schutz, Y., Acheson, K. J., Baertschi, P., \& Jequier, E. (1986). Energy expenditure by doubly labeled water: Validation in humans and proposed calculation. American Journal of Physiology: Regulatory, Integrative, and Comparative Physiology, 250(5 Pt 2), R823-R830.

Slater, B., Philippi, S. T., Marchioni, D. M. L., \& Fisberg, R. M. (2003). Validação de Questionários de Frequência AlimentarQFA: Considerações metodológicas [Validation of Food Frequency Questionnaires-FFQ: Methodological considerations]. Revista Brasileira de Epidemiologia, 6(3), 200-208. 
Talmage, H., \& Rasher, S. P. (1981). Validity and reliability issues in measurement instrumentation. Journal of Nutrition Education, 13(3), 83-85.

U.S. Department of Agriculture, Agricultural Research Service (2001) National Nutrient Database for Standard Reference: Release 25. [http://ndb.nal.usda.gov/ndb/search/list; accessed May 23, 2013]

Watson, L. C., Kwon, J., Nichols, D., \& Rew, M. (2009). Evaluation of the nutrition knowledge, attitudes, and food consumption behaviors of high school students before and after completion of a nutrition course. Family and Consumer Sciences Research Journal, 37(4), 523-534.
Wilson, A. M., Magarey, A. M., \& Mastersson, N. (2008). Reliability and relative validity of a child nutrition questionnaire to simultaneously assess dietary patterns associated with positive energy balance and food behaviours, attitudes, knowledge and environments associated with healthy eating. International Journal of Behavioral Nutrition and Physical Activity, 5(1), 5.

Yaroch, A. L., Resnicow, K., Davis, M., Davis, A., Smith, M, \& Khan, L. K. (2000). Development of a modified picture-sort food frequency questionnaire administered to low-income, overweight, African-American adolescent girls. Journal of the American Dietetic Association, 100(9), 1050-1056. 